\title{
'Apache' and 'Kettleman': Two Early Season Apricots for the Fresh Market
}

Craig A. Ledbetter ${ }^{1}$ and Sharon J. Peterson

U.S. Department of Agriculture, Agricultural Research Service, San Joaquin Valley Agricultural Sciences Center, Crop Diseases, Pests and Genetics Research Unit, 9611 South Riverbend Avenue, Parlier, CA, 93648-9757

Additional index words. fruit breeding, fruit quality, Prunus armeniaca L., self-incompatibility

'Apache' and 'Kettleman' are two new early-season apricots recently introduced for fresh market sales. They were developed by the Agricultural Research Service's Prunus breeding program in Parlier, Calif., and introduced in 2002 and 2005, respectively. Both of the new cultivars are self-incompatible and require other early flowering apricot cultivars to facilitate pollination and fruit set. With appropriate pollenizers, both 'Apache' and 'Kettleman' are extremely productive. At commercial maturity, fruit of 'Apache' are characterized by an almost translucent golden-orange skin color and a mild pink-red blush, while skin color of 'Kettleman' is a solid deep orange. Flesh of both cultivars is fine textured and juicy, with excellent eating quality at commercial maturity. Both new cultivars mature before the major tonnage cultivar 'Castlebrite,' with 'Apache' maturing about 7 to $10 \mathrm{~d}$ before 'Kettleman' and $11 \mathrm{~d}$ before 'Castlebrite.'

\section{Origins}

'Kettleman,'tested as K706-88, was identified in an open-pollinated population of apricot selection K104-98. 'A pache' apricot (tested as P301-105) arose from the cross of K149-70 (female parent) and K604-19 (male parent). Pedigrees of both new apricots are displayed in

Received for publication 27 June 2005. Accepted for publication 3 Aug. 2005.

${ }^{1}$ To whom reprint requests should be addressed.
Fig. 1. Both of the apricots were first selected in May, 1992. These specific seedling trees were selected on the basis of earliness in fruit maturity and high fruit quality as compared with standard commercial apricot cultivars grown in San Joaquin Valley, Calif.

\section{Description}

\section{Tree characteristics}

Trees of 'Apache' are upright in branch growth habit and demonstrate extremely strong vigor as compared with reference cultivars (Guerriero and Watkins, 1984). As such, 'Apache' trees can be pruned easily and appropriate 1-year-old wood selected for continuous renewal of fruiting spurs. The upright growth habit makes 'Apache' suitable for both trellised and traditional nonsupported tree planting arrangements. Fruit production of 'Apache' occurs on both fruiting spurs and along 1-year-old shoots. Larger fruit sizes are always obtained from those fruit that developed on spurs as opposed to 1-year-old shoots. The branch growth habit of 'Kettleman' is much more spreading as compared to 'Apache.' Like 'Apache,' 'Kettleman' trees exhibit extremely strong vigor, and are also easy to prune. Fruiting spurs are easily replenished from the large supply of annual shoots present throughout the tree. Both 1-year-old shoots and spurs are fruitful with largest fruit developing from the strongest spurs. 'Kettleman's' spreading growth branch habit makes the tree most suitable for an open vase tree form.
Flowering characteristics

Flowers of both 'Apache' and 'Kettleman' are male fertile and self-incompatible, and other apricot cultivars are necessary for adequate pollination and fruit set. As can be seen in Table 1, 'Apache' consistently blooms slightly before 'Kettleman,' although their bloom periods do normally overlap. However, controlled reciprocal pollinations between 'Apache' and 'Kettleman' apricots during three bloom seasons, have consistently shown that these new cultivars are inadequate pollenizers for one another. While not a complete failure at effecting pollination, fruit set is commercially inadequate when 'Apache' and 'Kettleman' are grown together and forced to pollinate reciprocally. For this reason, the apricot cultivar 'Katy' is a recommended pollenizer for 'Apache,' and 'Poppy' is recommended to pollenize 'Kettleman.' Controlled reciprocal pollinations between these two pairs of apricots have consistently yielded abundant fruit set. The suitability of other commercial apricot cultivars with blooms that overlap those of 'Apache' and 'Kettleman' has not been specifically studied.

\section{Fruit characteristics}

Fruit size, firmness, and color. Physical measurements of the new cultivars 'Apache' and 'Kettleman' are presented in Table 2 along with those of 'Castlebrite' apricot as a standard of comparison. The values presented represent average \pm standard error for each variable from two separate harvests for each of three consecutive years. At each harvest, attempts were made to select those fruit that represented commercial maturity based on fruit firmness and skin color. Fruit firmness was measured on a freshly cut fruit surface (skin removed) using a hand-held penetrometer equipped with an 8-mm tip (D. BallaufMfg. Co., Wash., D.C.). A chromameter (CR-200; Minolta Camera Co., Ltd., Osaka, Japan) was used to obtain CIELAB coordinates ' $L$,' ' $a$ ' and ' $b$ ' for flesh color determination. The CR-200 Meter was calibrated to a standard white tile (calibration plate CR-A43) each morning before any color analysis. As suggested by McGuire (1992), coordinates 'a' and ' $b$ ' were used to calculate
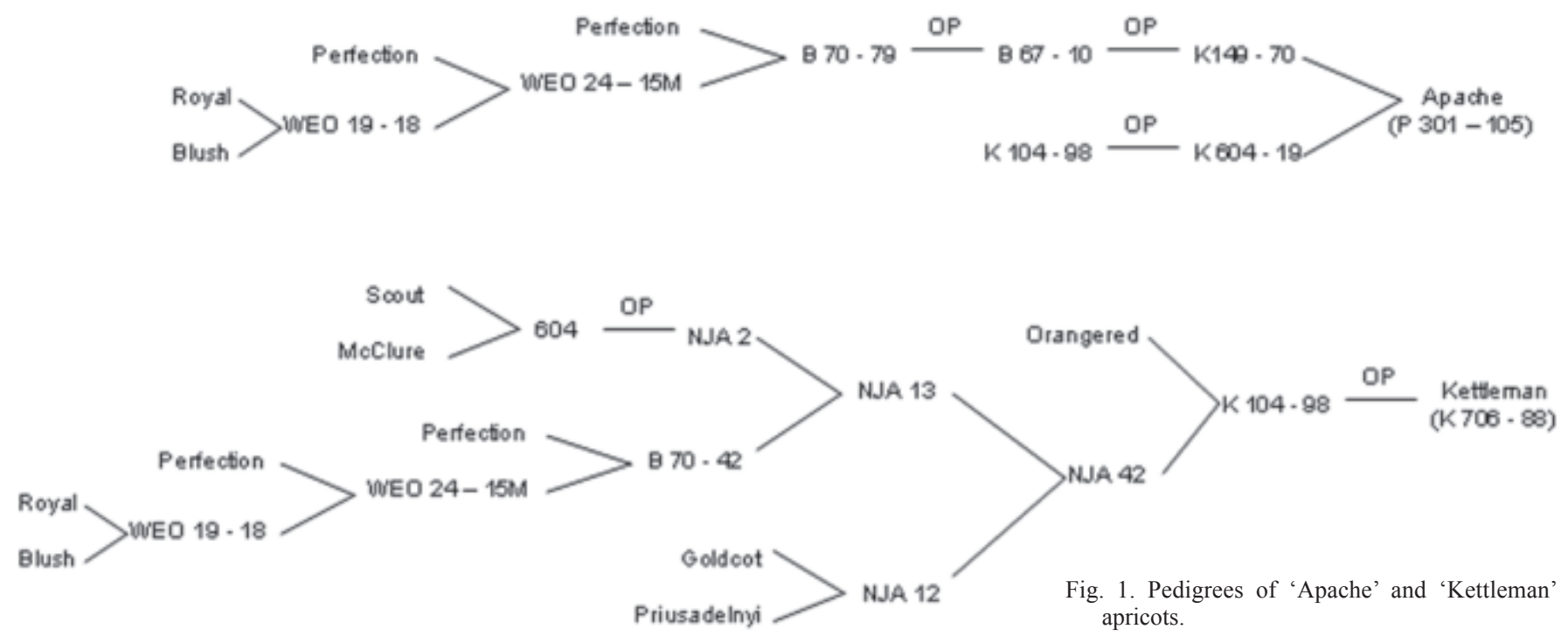
Table 1. Three years of bloom ranges (first bloom to full bloom) in Parlier, Fresno County, Calif., for new ARS apricots 'Apache' and 'Kettleman,' as well as reference cultivars 'Katy,' 'Poppy', and 'Castlebrite.'

\begin{tabular}{|c|c|c|c|c|c|c|}
\hline \multirow[b]{3}{*}{ Crop year } & \multicolumn{4}{|c|}{ ARS cultivars } & & \\
\hline & \multicolumn{2}{|c|}{ Apache } & \multicolumn{2}{|c|}{ Kettleman } & & \\
\hline & First $^{z}$ & Fully $^{y}$ & First & Full & & \\
\hline 2003 & $6 \mathrm{Feb}$ & $19 \mathrm{Feb}$ & $13 \mathrm{Feb}$ & $25 \mathrm{Feb}$ & & \\
\hline 2004 & $15 \mathrm{Feb}$ & $26 \mathrm{Feb}$ & $19 \mathrm{Feb}$ & 1 Mar. & & \\
\hline \multirow[t]{4}{*}{2005} & 7 Feb & $16 \mathrm{Feb}$ & $12 \mathrm{Feb}$ & 19 Feb. & & \\
\hline & \multicolumn{6}{|c|}{ Reference cultivars } \\
\hline & \multicolumn{2}{|c|}{ Katy } & \multicolumn{2}{|c|}{ Poppy } & \multicolumn{2}{|c|}{ Castlebrite } \\
\hline & First & Full & First & Full & First & Full \\
\hline 2003 & 7 Feb. & $18 \mathrm{Feb}$. & 11 Feb. & $20 \mathrm{Feb}$ & 13 Feb. & 4 Mar. \\
\hline 2004 & 14 Feb. & 25 Feb. & 14 Feb. & 23 Feb. & 19 Feb. & 4 Mar. \\
\hline 2005 & 4 Feb. & $15 \mathrm{Feb}$. & 4 Feb. & 16 Feb. & 14 Feb. & 20 Feb. \\
\hline
\end{tabular}

${ }^{\mathrm{z}}$ First bloom represents date at which $<1 \%$ of the flowers have opened.

${ }^{y}$ Full bloom represents date at which $>80 \%$ of flowers have opened.

Table 2. Fruit characteristic comparison (Mean \pm SEM) of 'Apache,' 'Kettleman', and 'Castlebrite' apricots grown in Parlier, Calif., 2002 through 2004.

\begin{tabular}{lccc}
\hline $\begin{array}{l}\text { Fruit } \\
\text { characteristic }\end{array}$ & Apache & Kettleman & Castlebrite \\
\hline Physical characteristic & & \\
$\quad$ Fruit mass $(\mathrm{g})$ & $61.5 \pm 1.4$ & $85.3 \pm 2.0$ & $70.0 \pm 1.7$ \\
$\quad$ Axial diameter $(\mathrm{mm})$ & $47.5 \pm 0.4$ & $53.4 \pm 0.4$ & $48.7 \pm 0.4$ \\
$\quad$ Flesh firmness $(\mathrm{N})$ & $25.4 \pm 1.5$ & $29.1 \pm 2.2$ & $20.7 \pm 1.7$ \\
$\quad$ Flesh hue $\left({ }^{\circ}\right)$ & $73.8 \pm 0.6$ & $69.3 \pm 0.7$ & $76.6 \pm 1.0$ \\
Juice characteristic & & & $12.8 \pm 0.3$ \\
$\quad{ }^{\circ}$ Brix & $15.0 \pm 0.4$ & $3.30 \pm 0.07$ & $3.35 \pm 0.06$ \\
pH & $3.29 \pm 0.06$ & $1.23 \pm 0.12$ & $1.00 \pm 0.08$ \\
$\quad$ acid (Meq/100 mL) & $1.23 \pm 0.08$ & 16 May & 18 May \\
Fruit maturity date & 7 May &
\end{tabular}

${ }^{\mathrm{z}}$ Calculated values based on two separate harvests per accession per year, seven fruit evaluated per harvest, three consecutive harvest years.

${ }^{y}$ Calculated values based on two separate composite juice samples derived from seven evaluated fruit at each of two harvests per accession, over three consecutive harvest years.

hue angle $\left(\mathrm{h}^{\circ}\right)$, which is accepted as a more intuitively understandable representation of visual color. 'Kettleman' is the largest of the three apricots in terms of fruit mass and axial diameter. 'Apache' is the smallest of the three apricots, but it is harvested much in advance of both 'Kettleman' and 'Castlebrite.' Averaged across the six evaluated harvests, 'Kettleman' lowest for 'Castlebrite' (Table 2). The three apricots exhibited similar juice $\mathrm{pH}$ values, all relatively low as is typical of early season apricots grown in San Joaquin Valley. Titratable acidity of apricot juice was lowest in 'Castlebrite' (1.00 Meq/100 mL) with equal average values $(1.23 \mathrm{Meq} / 100 \mathrm{~mL})$ for both 'Apache' and 'Kettleman.' Juice of 'Apache' is noticeably more aromatic than that of either 'Kettleman' or 'Castlebrite.'

Fruitmaturation time. When trees of similar age are grown in the same orchard and on the same rootstock, 'Apache' fruit mature about $9 \mathrm{~d}$ ahead of 'Kettleman' and 11 days ahead of 'Castlebrite' (Table 2). 'Kettleman' fruit maturation is nearly synchronous throughout the tree and complete harvest is accomplished with one to two passes. Fruit maturation of 'Apache' is not synchronous, and three or more harvests are required to obtain only those fruit of a specific color or firmness.

\section{Availability}

Mother trees of both 'Apache' and 'Kettleman' are located at the Agricultural Research Service's San Joaquin Valley Agricultural Sciences Center in Parlier. The new cultivars are considered free, with no restrictions placed on propagation or availability. Neither 'Apache' nor 'Kettleman' are patented in the U.S. or in any other country. Dormant budwood is usually available upon request. Proven virusfree budwood is available from the National Research Support Project 5 (NRSP5) in Prosser, Wash.

\section{Literature Cited} other two apricots, and had the deepest orange flesh (indicative of lower hue values). By comparison, evaluated 'Castlebrite' fruit had the least firmness and lightest orange flesh color averaged across all harvests.

Juice characteristics. Juice ${ }^{\circ}$ Brix was highest in evaluated fruit of 'Apache' and
Guerriero, R. and R. Watkins. 1984. Revised descriptor list for apricot (Prunus armeniaca L.). Intl. Board Plant Genet. Resour., Rome, Italy.

McGuire, R.G. 1992. Reporting objective color measurements. HortScience 27:1254-1255. 